\title{
Time Seeing a Hand Surgeon Is Not Associated With Patient Satisfaction
}

\author{
Teun Teunis MD, Emily R. Thornton BSc, \\ Prakash Jayakumar MD, David Ring MD, PhD
}

Received: 14 September 2014/ Accepted: 25 November 2014/Published online: 5 December 2014

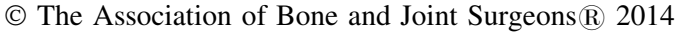

\begin{abstract}
Background Previous studies, predominantly in the primary care setting, identified time spent with the physician as an important predictor of satisfaction. It is unknown if the same holds true in hand surgery.

Questions/purposes Is patient satisfaction measured immediately after an office visit associated with the duration of time spent with the hand surgeon? What other factors are associated with satisfaction directly after the visits and 2 weeks after the appointment?
\end{abstract}

\begin{abstract}
One of the authors (DR) certifies that he, or a member of his immediate family, has or may receive payments or benefits, during the study period, from Wright Medical (Memphis, TN, USA) of less than USD 10,000; Skeletal Dynamics (Miami, FL, USA) of less than USD 10,000; Biomet (Warsaw, IN, USA) of less than USD 10,000; AO North America (Paoli, PA, USA) of less than USD 10,000; and AO International (Dubendorf, Switzerland) of less than USD 10,000. All ICMJE Conflict of Interest Forms for authors and Clinical Orthopaedics and Related Research ${ }^{\mathbb{B}}$ editors and board members are on file with the publication and can be viewed on request.

Clinical Orthopaedics and Related Research ${ }^{\mathbb{R}}$ neither advocates nor endorses the use of any treatment, drug, or device. Readers are encouraged to always seek additional information, including FDAapproval status, of any drug or device prior to clinical use.

Each author certifies that his or her institution approved the human protocol for this investigation, that all investigations were conducted in conformity with ethical principles of research, and that informed consent for participation in the study was obtained.
\end{abstract}

Electronic supplementary material The online version of this article (doi:10.1007/s11999-014-4090-z) contains supplementary material, which is available to authorized users.

T. Teunis, E. R. Thornton, P. Jayakumar, D. Ring ( $\square)$ Orthopaedic Hand and Upper Extremity Service, Massachusetts General Hospital, Harvard Medical School, 55 Fruit Street, Boston, MA 02114, USA

e-mail: dring@mgh.harvard.edu; dring@partners.org
Methods We prospectively enrolled 81 patients visiting our hand and upper extremity surgery outpatient clinic. We recorded their demographics and measured physical function, pain behavior, symptoms of depression, time spent in the waiting room, time spent with the physician, and patient satisfaction. Office times were measured using our patient ambulatory tracking system and by a research assistant outside the clinic room. To assess satisfaction we used items from the Consumer Assessment of Healthcare Providers and Systems survey (a federally developed standardized survey instrument) relevant to our study. Two weeks later, 51 (64\%) patients were available for telephone followup and the same measures were completed. Mean time spent with the hand surgeon was $8 \pm 5$ minutes and mean in-office wait time to see the hand surgeon was $32 \pm 18$ minutes. A priori power analyses indicated that 77 patients would provide $80 \%$ power to detect an effect size $\mathrm{f}^{2}=0.18$ for a regression with five predictors. This means that we would detect time spent with the physician as a significant factor if it accounted for $7 \%$ or more of the variability in satisfaction.

Results Time spent with the hand surgeon was not associated with patient satisfaction measured directly after the visit $(r=-0.023 ; p=0.84)$. Longer time waiting to see the physician correlated with decreased patient satisfaction $(\mathrm{r}=-0.30 ; \mathrm{p}=0.0057)$. The final multivariable model for increased satisfaction directly after the office visit included shorter waiting time (regression coefficient $[\beta]-0.0014$; partial $\mathrm{R}^{2} 0.094 ; 95 \%$ confidence interval $[\mathrm{CI}],-0.0024$ to $-0.00042 ; \mathrm{p}=0.006)$ and being married/living with a partner ( $\beta$ 0.057; partial $\mathrm{R}^{2} 0.11$; 95\% CI, 0.021-0.093; $\mathrm{p}=0.002$ [adjusted $\mathrm{R}^{2} 0.18 ; \mathrm{p}<0.001$ ]). Similarly, multivariable analysis found higher patient satisfaction 2 weeks after the visit to be independently associated with shorter waiting time ( $\beta-0.0037$; partial $\mathrm{R}^{2} 0.10$; $95 \% \mathrm{CI}$, 
-0.0070 to $-0.00054 ; \mathrm{p}=0.023)$ and being married/living with a partner $\left(\beta\right.$ 0.15; partial $\mathrm{R}^{2} 0.12$; 95\% CI, 0.033-0.26; $\mathrm{p}=0.012$ [adjusted $\mathrm{R}^{2} 0.16 ; \mathrm{p}=0.0052$ ]).

Conclusions Patient satisfaction among patients undergoing hand surgery may relate more to shorter time in the waiting room and to the quality more than the quantity of time spent with the patient.

Level of Evidence Level II, prognostic study.

\section{Introduction}

Patient satisfaction is used as a measure of quality of care [19]; however, research to date suggests that patient satisfaction is related to more than how effectively the physician manages the patient's specific medical problems [9, 18, 20, 29]. Previous studies, predominantly in the primary care setting, identified time spent with the physician as an important predictor of patient satisfaction $[3,8$, $12,26]$. Most of the studies on time spent in the office uses a cross-sectional survey design in which patients are asked - at a time remote from the visit-about their satisfaction and their perceived waiting time and time with the physician $[3,8,14,15,27,30]$. An objective measure of time is needed because satisfied and dissatisfied patients might have differently biased estimates of these times.

It is not known if time spent with the physician is an important predictor of patient satisfaction in hand surgery and orthopaedic surgery. Many of our patients have simple problems (eg, evaluation after cortisone injection, healed hand fracture) for which they might rate an efficient office visit as more satisfying. Conversely, some patients have puzzling problems or problems that do not yet have a ready solution. It is not clear that a longer visit is more satisfying for these patients either. In fact, experts in communication skills emphasize that the length of the encounter is not nearly as important as the quality of the encounter [1, 24, 25], but formal studies of this are lacking and this concept is counterintuitive to hand and orthopaedic surgeons. The idea is that as long as patients feel that their caregivers understand and care about them, they may not need an extended visit time to feel satisfied [24, 25]. If data show no correlation between the duration of the appointment and satisfaction, then our attention may be better placed on the quality rather than the quantity of the communication.

Our study addressed the primary null hypothesis that satisfaction measured immediately after an office visit is not associated with the duration of time spent with the physician. Secondary study questions addressed the relationship of satisfaction with the duration of wait time to see the physician as well as factors associated with satisfaction directly after the visit and 2 weeks after the appointment.

\section{Materials and Methods}

After institutional review board approval of the prospective observational cohort study, we enrolled 84 adult patients between January 14 and May 6, 2014, who were seen at the hand and upper extremity service at our academic Level I trauma center. We included all new and followup patients, who were aged 18 years and older, visiting a single provider (senior author, DR). We excluded pregnant women, patients younger than 18 years old, and patients unable to speak English or unable to give informed consent. Seven patients declined participation because they were not interested in the study. A researcher (ERT, not involved with patient treatment) obtained informed consent before patients saw their physician. Patients filled out their age, sex, traumatic versus discrete diagnosis, comorbidities, tobacco use, marital status, and work status in addition to the following questionnaires: the validated Patients Reported Outcome Measurement Information System (PROMIS) physical function-upper extremity [13], PROMIS pain interference [2], and PROMIS depression [22]. Average time necessary to complete these questionnaires was $5 \pm 2$ minutes (range, 2-13 minutes). Office times were measured using our patient ambulatory tracking system and by the research assistant outside the clinic room. Patient satisfaction was measured after completion of the visit using four items of the Consumer Assessment of Healthcare Providers and Systems survey (a federally developed standardized survey instrument) [10]. All questionnaires were administered through Assessment Center (Northwestern University, Evanston, IL, USA), a webbased data collection tool, on a tablet computer [11].

Patients were contacted by telephone after 2 weeks and again completed the PROMIS physical function-upper extremity and the satisfaction survey.

\section{Outcome Measures}

We used the computerized adaptive testing (CAT) instruments for all PROMIS questionnaires. CAT provides patients with a maximum of 12 questions in a dynamic order with the content determined by the response to the prior question. The method reduces administration time and flooring and ceiling effects. PROMIS CAT items include five response options ranging from 1 ("not at all") to 5 ("very much"). The total score capacity of each PROMIS instrument ranges from 0 to 100 points. A score of 50 represents the mean score of the general US population [4]. Higher scores indicate higher levels of the construct measured (eg, function, depression).

PROMIS physical function-upper extremity measures disability with physical activities that involve various upper limb activities [13]. PROMIS pain interference CAT 
addresses the degree to which pain interferes with patient ability to achieve their goals [2]. PROMIS depression CAT evaluates nonsomatic symptoms of depression [22].

Our patient ambulatory tracking system records the moment a patient registers at the front desk. The research assistant recorded the time the physician entered the room. We defined waiting time as the difference between both measurements. The same research assistant, while waiting outside the room, used a stopwatch to measure the time the physician and patients spent together.

Patient satisfaction was measured using four communication report items from the Consumer Assessment of Healthcare Providers and Systems survey (measure for the adult visit survey) [10]. Participants were asked to rate the following items: "provider listened carefully to the patient"; "provider showed respect for what the patient had to say"; and "provider spent enough time with the patient." Possible responses were "yes, definitely," "yes, somewhat," and "no." As the fourth item, patients rated their provider on an 11-point ordinal scale. To weigh all items equally in the composite satisfaction score, this score was changed into three categories: the first category contained scores ranging from 0 to 3 ; the second from 4 to 7 ; and the third from 8 to 10 . A possible satisfaction score ranging from 0 to 1 was computed as the mean of the responses to the four items with a higher score indicating greater satisfaction.

\section{Study Population}

We excluded three patients of whom no front desk registration time was available from our patient ambulatory tracking system. The remaining 81 patients had a mean age of $49 \pm 15$ years (range, $22-81$ years) and $46 \%$ (37) were men (Table 1). Their exact diagnoses are listed in Appendix 1 (Supplemental materials are available with the online version of CORR ${ }^{\circledR}$.). Fifty-six percent (45) were new patient visits; the remainder consisted of patients attending followup appointments. Forty-two percent (34) of the visits related to a previous trauma. Fifty-two patients $(64 \%)$ were also available 2 weeks later (mean, $13 \pm 6.2$ days) for followup. The rate of loss to followup is high but not unusual for prospective research at our department [21]. We compared responders and nonresponders and found no differences in baseline characteristics, office times, and satisfaction (Appendix 2 [Supplemental materials are available with the online version of $\operatorname{CORR}^{\circledR}$.]).

\section{Statistical Analysis}

Continuous variables are presented as mean $\pm \mathrm{SD}$ and discrete data as proportions. Unpaired t-test and one-way
Table 1. Study patient characteristics

\begin{tabular}{|c|c|c|}
\hline Demographics & Enrollment & Followup \\
\hline Number of patients & 81 & 52 \\
\hline Age (years; range) & $49 \pm 15(22-81)$ & $51 \pm 14(26-81)$ \\
\hline Men & $46 \%(37)$ & $46 \%(24)$ \\
\hline Diagnosis related to injury & $42 \%(34)$ & $40 \%(21)$ \\
\hline Additional comorbidities & $35 \%(28)$ & $27 \%(14)$ \\
\hline Circulatory & $14 \%(11)$ & $12 \%(6)$ \\
\hline Musculoskeletal & $11 \%(9)$ & $10 \%(5)$ \\
\hline Other & $10 \%(8)$ & $6 \%(3)$ \\
\hline \multicolumn{3}{|l|}{ Marital status } \\
\hline Single & $29 \%(23)$ & $21 \%(11)$ \\
\hline Partner/married & $57 \%(46)$ & $63 \%(33)$ \\
\hline Separated/widowed & $15 \%(12)$ & $15 \%(8)$ \\
\hline New patient & $56 \%(45)$ & $54 \%(28)$ \\
\hline Tobacco use & $11 \%(9)$ & $13 \%(7)$ \\
\hline Employed & $77 \%(62)$ & $75 \%(39)$ \\
\hline \multicolumn{3}{|l|}{ Patient-reported outcomes } \\
\hline PROMIS upper extremity & $39 \pm 11$ & $40 \pm 11$ \\
\hline PROMIS depression & $48 \pm 10$ & $45 \pm 12$ \\
\hline PROMIS pain interference & $58 \pm 9.1$ & $55 \pm 10$ \\
\hline \multicolumn{3}{|l|}{ Office times (minutes) } \\
\hline Wait time (range) & $32 \pm 18(8-84)$ & $31 \pm 17(8-76)$ \\
\hline Time with clinician (range) & $7.6 \pm 5.2(1-28)$ & $7.7 \pm 5.2(1-28)$ \\
\hline \multicolumn{3}{|l|}{ Satisfaction } \\
\hline \multicolumn{3}{|l|}{ Surgeon listened carefully } \\
\hline No & 0 & $4 \%(2)$ \\
\hline Somewhat yes & $4 \%(3)$ & $10 \%(5)$ \\
\hline Yes & $96 \%(78)$ & $86 \%(45)$ \\
\hline \multicolumn{3}{|l|}{ Surgeon showed respect } \\
\hline No & 0 & $2 \%(1)$ \\
\hline Somewhat yes & $1 \%(1)$ & $8 \%(4)$ \\
\hline Yes & $99 \%(80)$ & $90 \%(47)$ \\
\hline \multicolumn{3}{|c|}{ Surgeon spent enough time with the patient } \\
\hline No & $2 \%(2)$ & $6 \%(3)$ \\
\hline Somewhat yes & $12 \%(10)$ & $15 \%(8)$ \\
\hline Yes & $85 \%(69)$ & $79 \%(41)$ \\
\hline \multicolumn{3}{|l|}{ Rating of surgeon } \\
\hline $0-3$ & 0 & $4 \%(2)$ \\
\hline $4-7$ & $5 \%(4)$ & $8 \%(4)$ \\
\hline $8-10$ & $95 \%(77)$ & $88 \%(46)$ \\
\hline Aggregate satisfaction score & $0.96 \pm 0.1$ & $0.91 \pm 0.2$ \\
\hline
\end{tabular}

Continuous variables as mean $\pm \mathrm{SD}$; discrete variables as percentage (number); PROMIS = Patient Reported Outcome Measurement Information System.

analysis of variance were performed to determine the differences between continuous and dichotomous variables; Pearson correlation was used for comparison of two continuous variables. 
To test for confounding influence on patient satisfaction directly after the office visit and after the followup visit (approximately 2 weeks), we performed two stepwise backward multivariable linear regression analyses for all factors where $\mathrm{p}<0.10$ on bivariate analysis after changing all categorical values into dummy variables with the first variable exempted from analysis.

A power analysis indicated that a sample of 77 patients would provide $80 \%$ statistical power, with $\alpha$ set at 0.05 , for an effect size $\mathrm{f}^{2}=0.18$ for a regression with five predictors. This means that we would detect time spent with the physician as a significant factor if it accounted for $7 \%$ or more of the variability in satisfaction, and based on previous studies, we assume our complete model would account for $34 \%$ of the variability $[3,8]$.

\section{Results}

Time spent with the physician was not associated with patient satisfaction measured directly after the visit $(\mathrm{r}=$ $-0.023 ; \mathrm{p}=0.84$; Table 2).

Longer time waiting to see the physician correlated with decreased satisfaction directly after the visit $(r=-0.30$; $p=0.0057$ ). The final multivariable model for increased patient satisfaction directly after the office visit included shorter waiting time (regression coefficient $[\beta]-0.0014$; partial $\mathrm{R}^{2} 0.094$; $95 \%$ confidence interval $[\mathrm{CI}],-0.0024$ to $-0.00042 ; \mathrm{p}=0.006)$ and being married/living with a partner ( $\beta$ 0.057; partial $\mathrm{R}^{2} 0.11$; 95\% CI, 0.021-0.093; $\mathrm{p}=0.002$ [adjusted $\mathrm{R}^{2} 0.18 ; \mathrm{p}<0.001$ ]). In the preliminary bivariate analysis, in addition to wait time, having no additional comorbidities and having a partner or being married were also associated with patient satisfaction. Similarly, multivariable analysis showed higher patient satisfaction 2 weeks after the visit was independently associated with shorter wait time $\left(\beta-0.0037\right.$; partial $\mathrm{R}^{2} 0.10$; $95 \% \mathrm{CI}$, 0.0070 to $-0.00054 ; \mathrm{p}=0.023$ ) and being married/living with a partner ( $\beta 0.15$; partial $\mathrm{R}^{2} 0.12$; $95 \%$ CI, $0.033-0.26$, $\mathrm{p}=0.012$ [adjusted $\mathrm{R}^{2} 0.16 ; \mathrm{p}=0.0052$ ]; Table 3).

\section{Discussion}

Patient satisfaction is increasingly used as a metric of quality of care. We need a better understanding of patient satisfaction to know whether it is a good quality measure for hand surgeons. In the primary care setting, time spent with the physician correlates with patient satisfaction. Many surgeons intuitively feel that if they spend more time with a patient, they can satisfy the patient's needs, but communication experts emphasize quality over quantity of communication $[1,24,25]$. Our study found that time spent with the hand
Table 2. Bivariate analysis satisfaction and independent variables

\begin{tabular}{|c|c|c|c|c|}
\hline \multirow[t]{2}{*}{ Demographics } & \multicolumn{3}{|l|}{ Satisfaction } & \multirow[t]{2}{*}{$\mathrm{p}$ value } \\
\hline & $\begin{array}{l}\text { Directly } \\
\text { after visit }\end{array}$ & $\mathrm{p}$ value & $\begin{array}{l}2 \text { weeks } \\
\text { after visit }\end{array}$ & \\
\hline Age (r) & 0.15 & 0.18 & 0.19 & 0.17 \\
\hline \multicolumn{5}{|l|}{ Sex } \\
\hline Men & $0.97 \pm 0.1$ & 0.52 & $0.93 \pm 0.21$ & 0.62 \\
\hline Women & $0.96 \pm 0.1$ & & $0.90 \pm 0.22$ & \\
\hline \multicolumn{5}{|l|}{ Diagnosis } \\
\hline Discrete & $0.96 \pm 0.1$ & 0.48 & $0.92 \pm 0.19$ & 0.74 \\
\hline Traumatic & $0.97 \pm 0.1$ & & $0.90 \pm 0.24$ & \\
\hline \multicolumn{5}{|l|}{ Comorbidities } \\
\hline Yes & $0.93 \pm 0.13$ & 0.014 & $0.82 \pm 0.28$ & 0.064 \\
\hline No & $0.98 \pm 0.049$ & & $0.94 \pm 0.17$ & \\
\hline \multicolumn{5}{|l|}{ Marital status } \\
\hline Single & $0.95 \pm 0.090$ & 0.0016 & $0.86 \pm 0.30$ & 0.041 \\
\hline Partner/married & $0.99 \pm 0.031$ & & $0.96 \pm 0.10$ & \\
\hline $\begin{array}{l}\text { Separated/ } \\
\text { widowed }\end{array}$ & $0.90 \pm 0.17$ & & $0.77 \pm 0.34$ & \\
\hline \multicolumn{5}{|l|}{ New patient } \\
\hline Yes & $0.95 \pm 0.11$ & 0.13 & $0.91 \pm 0.20$ & 0.99 \\
\hline No & $0.98 \pm 0.053$ & & $0.91 \pm 0.23$ & \\
\hline \multicolumn{5}{|l|}{ Smoking } \\
\hline Yes & $0.96 \pm 0.093$ & 0.22 & $0.96 \pm 0.094$ & 0.48 \\
\hline No & $1.0 \pm 0.0$ & & $0.90 \pm 0.22$ & \\
\hline \multicolumn{5}{|l|}{ Employed } \\
\hline Yes & $0.97 \pm 0.084$ & 0.76 & $0.90 \pm 0.24$ & 0.43 \\
\hline No & $0.96 \pm 0.090$ & & $0.95 \pm 0.081$ & \\
\hline \multicolumn{5}{|c|}{ Patient-reported outcomes (r) } \\
\hline $\begin{array}{l}\text { PROMIS upper } \\
\text { extremity }\end{array}$ & 0.16 & 0.16 & 0.12 & 0.40 \\
\hline $\begin{array}{l}\text { PROMIS } \\
\text { depression }\end{array}$ & -0.20 & 0.077 & -0.17 & 0.23 \\
\hline $\begin{array}{l}\text { PROMIS pain } \\
\text { interference }\end{array}$ & -0.10 & 0.38 & -0.12 & 0.39 \\
\hline \multicolumn{5}{|l|}{ Office times (r) } \\
\hline Wait time & -0.30 & 0.0057 & -0.29 & 0.039 \\
\hline $\begin{array}{l}\text { Time with } \\
\text { clinician }\end{array}$ & -0.023 & 0.84 & 0.11 & 0.44 \\
\hline
\end{tabular}

Values are mean $\pm \mathrm{SD}$, unless otherwise indicated; bold indicates significant difference; PROMIS = Patient Reported Outcome Measurement Information System.

surgeon was not associated with patient satisfaction. By contrast, shorter waiting time and being married/living with a partner were independent predictors of patient satisfaction.

Our study has some limitations. First, we only included patients treated by a single provider. Multiple hand surgeons work at our clinic, but many surgeons are uncomfortable with studies of patient satisfaction. A single provider reduces the effect of different practice styles but also diminishes the generalizability of our results. Second, 
Table 3. Multivariable analysis: patient satisfaction after office visit and at 2 weeks

\begin{tabular}{|c|c|c|c|c|}
\hline Retained variables & $\beta$ regression coefficient $(95 \% \mathrm{CI})$ & $\mathrm{p}$ value & Partial $\mathrm{R}^{2}$ & Adjusted $\mathrm{R}^{2}$ \\
\hline \multicolumn{5}{|l|}{ Directly after visit } \\
\hline Wait time & $-0.0014(-0.0024$ to -0.00042$)$ & 0.006 & 0.094 & 0.18 \\
\hline Marital status: partner or married & $0.057(0.021-0.093)$ & 0.002 & 0.11 & \\
\hline \multicolumn{5}{|l|}{ After 2 weeks } \\
\hline Wait time & $-0.0037(-0.0070$ to -0.00054$)$ & 0.023 & 0.10 & 0.16 \\
\hline Marital status: partner or married & $0.15(0.033-0.26)$ & 0.012 & 0.12 & \\
\hline
\end{tabular}

$\mathrm{CI}=$ confidence interval.

only $65 \%$ (51 of 81 ) of the patients responded 2 weeks after the visit. The smaller sample limits the power of our secondary study question. If a factor accounted for less than $7 \%$ of the variability in satisfaction, it would be missed. We found no difference between nonresponders and patients available for followup. Loss seems unrelated to different office times or satisfaction. Third, there was high satisfaction overall, which may have affected the statistical analysis. It might be better to study less satisfying diagnoses such as puzzling pain. The current cohort only included three nonspecific diagnoses (Appendix 1). Fourth, patients were informed about the study's goal to assess patient satisfaction and time spent in the office, which might have made them more aware of wait time. We aimed to decrease interference of our study with the actual clinic visit by measuring time spent with the physician outside the clinic room. Fifth, all of the office visits were extended to a longer than usual time by completing the questionnaires. Although none of this extra time was with the surgeon, the research might have satisfied patients' social needs and other aspects of a doctor visit. Sixth, we included items from the Consumer Assessment of Healthcare Providers and Systems survey relevant to our study. Our composite score is not separately validated, possibly limiting the reliability of our satisfaction measure. Validation of most satisfaction instruments is limited and research on patient satisfaction in general would benefit from a more thoroughly validated and serviceable satisfaction instrument. Also, to weigh all items equally in our composite satisfaction score, we had to reduce the 11-point provider rating to a 3-point scale also used for the other items. This resulted in a loss of data width for this item. Lastly, our multivariable models could only explain a limited amount of the variation in patient satisfaction. The unaccounted for variability probably relates to some combination of unmeasured factors in the process of care, psychological factors, and "noise" in the data (eg, patients misunderstanding the questionnaires or not being honest in their responses, difficulties with being precise, or waxing and waning level of attentiveness).
Our finding that time spent with the hand surgeon did not correlate with patient satisfaction is consistent with findings in emergency care [26] but inconsistent with findings in primary care [3]. It is unclear why time with the physician and satisfaction vary among medical specialties. Perhaps patients with a more focused problem are satisfied with an efficient visit, more so than patients who want to discuss and promote their health in general.

Longer wait time was associated with decreased patient satisfaction. The relationship between longer waiting time and decreased satisfaction for specialty outpatient office visits $[8,15,30]$, emergency medicine $[26,27]$, and primary care is consistent across studies [3, 6, 14, 23]. One study of surgery outpatients found that patients remained "reasonably satisfied" after up to 37 minutes of waiting time [15]. Also, together with the quality of the doctor's explanation, longer wait time was associated with patients deciding not to return to the same doctor in a variety of specialty outpatient clinics $[8,30]$. One study of an initiative to decrease wait time in a military primary care clinic documented improved patient satisfaction after the intervention [6], a strategy worth considering in orthopaedic practice.

Increased patient satisfaction immediately after the office visit and 2 weeks later were both independently associated with being married/living with a partner and time waiting for the physician. Judging by the partial $R^{2}$ value, marital status (a sociologic factor) was slightly more influential than time waiting for a hand surgeon. Prior studies indicate older age is independently associated with higher satisfaction, but that was not the case in our study $[12,16]$. Previous studies have shown that married people have lower rates of chronic limitations and disability [28], and when visiting a hand surgery clinic, married patients, in general, have lower disability measured by QuickDASH (Disabilities of the Arm, Shoulder and Hand) and PROMIS physical function questionnaires [17]. Less disability tends to reflect greater adaptation and resilience and may relate to increased satisfaction, something future studies could address. 
Wait time before seeing a hand surgeon is not associated with patient satisfaction, but shorter wait time and being married/living with a partner are. Prior studies have related satisfaction to psychological distress/depression [5, 29], unmet patient expectations [16], and less patient involvement in decision-making [7]. We speculate that satisfaction is partly a psychosocial phenomenon related to resiliency and partly related to the process of care (including elements like wait time and customer service). Hand and orthopaedic surgeons often have to deliver counterintuitive and unwelcome expert advice. For instance, we have to inform people that they have a degenerative condition such as arthritis or rotator cuff tendinopathy with no disease-modifying treatments; that many musculoskeletal pains (eg, back pain) remain puzzling and difficult to treat; or that commonly used treatments are likely no better than a placebo effect (eg, corticosteroid injection for lateral epicondylitis). It is particularly difficult to convey our expertise to patients with greater stress, distress, or ineffective coping strategies, patients for whom their musculoskeletal pain may be a somatic focus. If you also make the patient wait, you may be starting from behind, because the patient is already unhappy with you. Also consider the fact that you are likely stressed and wound up when you are behind and keeping patients waiting. Many surgeons have the impression that a little more time with the patient, one more explanation, will satisfy even the most dissatisfied patient. However, our study confirms what communication experts teach: it is not the duration, but likely the quality of the interaction that matters. We recommend scheduling office hours so that the surgeon does not get behind and has some time to take a break and keep from getting wound up; we recommend emphasizing active listening and empathy as a priority; expertise should be limited to scripted, bullet point facts about the illness, pausing and waiting for questions or permission to proceed (a nod is a good signal), and no attempt to convince patients who find this information counterintuitive. Just retreat to empathy ("I see that's not what you were expecting to hear") and make a clear action plan that does not involve excessive testing, use of unproved treatments, overmedicalization of the problem, or hindrance of the development of effective coping strategies (for instance, do not advise unnecessary rest or avoidance of activities). The effectiveness of such specific communication strategies could be tested prospectively in orthopaedic offices, measuring changes in patient and staff satisfaction and stress levels as these systems and skills are implemented and practiced. Studies might also measure different surgeons' practice and communication styles and see if they correlate with patient satisfaction.

\section{References}

1. American Academy of Orthopaedic Surgeons. Information statement 1017: patient-physician communication. 2011. Available at: http://www.aaos.org/about/papers/advistmt/1017.asp. Accessed August 17, 2008.

2. Amtmann D, Cook KF, Jensen MP, Chen WH, Choi S, Revicki D, Cella D, Rothrock N, Keefe F, Callahan L, Lai JS. Development of a PROMIS item bank to measure pain interference. Pain. 2010;150:173-182.

3. Anderson RT, Camacho FT, Balkrishnan R. Willing to wait?: the influence of patient wait time on satisfaction with primary care. BMC Health Serv Res. 2007;7:31.

4. Assessment Center. PROMIS terms and conditions. 2011. Available at: http://www.assessmentcenter.net/documents/ PROMISTermsandConditionsv7.3.pdf. Accessed November 11, 2014.

5. Bair MJ, Kroenke K, Sutherland JM, McCoy KD, Harris H, McHorney CA. Effects of depression and pain severity on satisfaction in medical outpatients: analysis of the Medical Outcomes Study. J Rehabil Res Dev. 2007;44:143-152.

6. Bar-dayan Y, Leiba A, Weiss Y, Carroll JS, Benedek P. Waiting time is a major predictor of patient satisfaction in a primary military clinic. Mil Med. 2002;167:842-845.

7. Bot AG, Bossen JK, Herndon JH, Ruchelsman DE, Ring D, Vranceanu AM. Informed shared decision-making and patient satisfaction. Psychosomatics. 2014 Jan 3 [Epub ahead of print].

8. Camacho F, Anderson R, Safrit A, Jones AS, Hoffmann P. The relationship between patient's perceived waiting time and officebased practice satisfaction. $N C$ Med J. 2006;67:409-413.

9. Chang JT, Hays RD, Shekelle PG, MacLean CH, Solomon DH, Reuben DB, Roth CP, Kamberg CJ, Adams J, Young RT, Wenger NS. Patients' global ratings of their health care are not associated with the technical quality of their care. Ann Intern Med. 2006; 144:665-672.

10. Crofton C, Lubalin JS, Darby C. Consumer Assessment of Health Plans Study (CAHPS). Foreword. Med Care. 1999;37:MS1-9.

11. Gershon R, Rothrock NE, Hanrahan RT, Jansky LJ, Harniss M, Riley W. The development of a clinical outcomes survey research application: Assessment Center. Qual Life Res. 2010;19:677-685.

12. Gross DA, Zyzanski SJ, Borawski EA, Cebul RD, Stange KC. Patient satisfaction with time spent with their physician. J Fam Pract. 1998;47:133-137.

13. Hays RD, Spritzer KL, Amtmann D, Lai JS, Dewitt EM, Rothrock N, Dewalt DA, Riley WT, Fries JF, Krishnan E. Upper-extremity and mobility subdomains from the PatientReported Outcomes Measurement Information System (PROMIS) adult physical functioning item bank. Arch Phys Med Rehabil. 2013;94:2291-2296.

14. Howard M, Agarwal G, Hilts L. Patient satisfaction with access in two interprofessional academic family medicine clinics. Fam Pract. 2009;26:407-412.

15. Huang XM. Patient attitude towards waiting in an outpatient clinic and its applications. Health Serv Manage Res. 1994;7:2-8.

16. Jackson JL, Chamberlin J, Kroenke K. Predictors of patient satisfaction. Soc Sci Med. 2001;52:609-620.

17. Janssen SJ, ter Meulen DP, Nota SPFT, Hageman MGJS, Ring D. Does verbal and non-verbal communication of pain correlate with disability? Psychosomatics. Available at: http://www.psychosomaticsjournal. com/article/S0033-3182\%2814\%2900084-X/abstract. Accessed November 25, 2014.

18. Lozano Calderon SA, Paiva A, Ring D. Patient satisfaction after open carpal tunnel release correlates with depression. J Hand Surg Am. 2008;33:303-307. 
19. Morris BJ, Jahangir AA, Sethi MK. Patient Satisfaction: an emerging health policy issue. AAOS Now. 2012;6. Available at: http://www. aaos.org/news/aaosnow/jun13/advocacy5.asp. Accessed November 25, 2014.

20. O’Toole RV, Castillo RC, Pollak AN, MacKenzie EJ, Bosse MJ, Group LS. Determinants of patient satisfaction after severe lowerextremity injuries. J Bone Joint Surg Am. 2008;90:1206-1211.

21. Ootes D, Buijze GA, Ring D. Predictors of missed appointments in prospective hand surgery research. Hand (N Y). 2012;7:177-180.

22. Pilkonis PA, Choi SW, Reise SP, Stover AM, Riley WT, Cella D, Group PC. Item banks for measuring emotional distress from the Patient-Reported Outcomes Measurement Information System (PROMIS $^{\mathbb{R}}$ ): depression, anxiety, and anger. Assessment. 2011; 18:263-283.

23. Probst JC, Greenhouse DL, Selassie AW. Patient and physician satisfaction with an outpatient care visit. J Fam Pract. 1997;45:418-425.
24. Schattner A. The silent dimension: expressing humanism in each medical encounter. Arch Intern Med. 2009;169:1095-1099.

25. Tongue JR, Epps HR, Forese LL. Communication skills. Instr Course Lect. 2005;54:3-9.

26. Trout A, Magnusson AR, Hedges JR. Patient satisfaction investigations and the emergency department: what does the literature say? Acad Emerg Med. 2000;7:695-709.

27. van Uden CJ, Ament AJ, Hobma SO, Zwietering PJ, Crebolder HF. Patient satisfaction with out-of-hours primary care in the Netherlands. BMC Health Serv Res. 2005;5:6.

28. Verbrugge LM. Marital status and health. Journal of Marriage and Family. 1979;41:267-285.

29. Vranceanu AM, Ring D. Factors associated with patient satisfaction. J Hand Surg Am. 2011;36:1504-1508.

30. Zoller JS, Lackland DT, Silverstein MD. Predicting patient intent to return from satisfaction scores. J Ambul Care Manage. 2001;24:44-50. 